\title{
CIDADES CRIATIVAS E REQUALIFICAÇÃO URBANA : consumo do espaço e dinâmica socioespacial na antiga estação ferroviária de Cordeirópolis (SP)
}

\author{
Eduardo Alberto Manfredini \\ Centro Universitário Adventista de São Paulo (UNASP) - Eng. Coelho (SP) \\ Universidade Estadual Paulista Julio de Mesquita Filho (UNESP) - Rio Claro (SP) \\ Orientadora: Profa. Dra. Silvia Aparecida Guarnieri Ortigoza \\ arqeam@terra.com.br
}

\begin{abstract}
RESUMO
O presente artigo é parte dos estudos de pós-doutoramento que tratam das ações humanas sobre o espaço urbano em uma cidade de pequeno porte, abordando as dinâmicas materiais reproduzidas neste cenário. Neste contexto analisa-se, um recorte da área urbana central do município paulista de Cordeirópolis localizado no leste paulista, na região interiorana de Campinas, terceira área de maior concentração industrial do país. - instalado no entroncamento das três principais Rodovias que conectam o Estado de São Paulo à região Centro Oeste e ao Estado de Minas Gerais. O objeto de estudos engloba a área da histórica Estação Ferroviária - instalada no ano de 1.876 e única no país implantada "em curva" - enquanto elemento de interesse aos estudos da ocupação socioespacial. O trabalho procura assim demonstrar utilizando-se de conceitos voltados à promoção de cidades criativas, sustentáveis e inteligentes - as possibilidades envolvidas em uma mudança de paradigmas na condução do planejamento urbano.
\end{abstract}

Palavras chaves: espaço urbano, Estação Ferroviária, cidades criativas e planejamento urbano.

\begin{abstract}
ABSTRTACT
This article is part of the post-doctoral studies dealing with human actions on the urban space in a small town, addressing the dynamic material reproduced in this scenario. In this context it is analyzed, a cutout from the central urban area of São Paulo Cordeirópolis - located in São Paulo's east, in the hinterland of Campinas, the third largest area of industrial concentration in the country - installed at the junction of three major highways that connect the State of São Paulo to the midwest and the state of Minas Gerais. The study object comprises the area of the historic train station - installed in the year 1876 and only one in the country located "in turn" - as an element of interest to socio-occupancy studies. The work thus seeks to demonstrate - using concepts aimed at the promotion of creative, sustainable and smart cities - the possibilities involved in a paradigm shift in the conduct of urban planning.
\end{abstract}

Key words: urban space, Railway Station, creative cities and urban planning. 


\section{CARACTERIZAÇÃO DO SOCIOESPAÇO}

Ao estudo do conjunto de ações, tanto públicas, quanto privadas, que tem como resultado a ocupação do território urbano, denomina-se dinâmica socioespacial.

Este tema é tratado neste trabalho, em conjunto com os estudos da economia criativa, abordada a seguir, relacionando-os às temáticas atreladas ao crescimento populacional, a evolução física da cidade, bem como sua formação e evolução, tendo como foco a área da antiga Estação Ferroviária de Cordeirópolis, cidade do interior paulista, localizada na Região de Campinas.

\section{LOCALIZAÇÃO DO MUNICIPIO DE CORDEIROPOLIS - ESTADO DE SĀO PAULO}

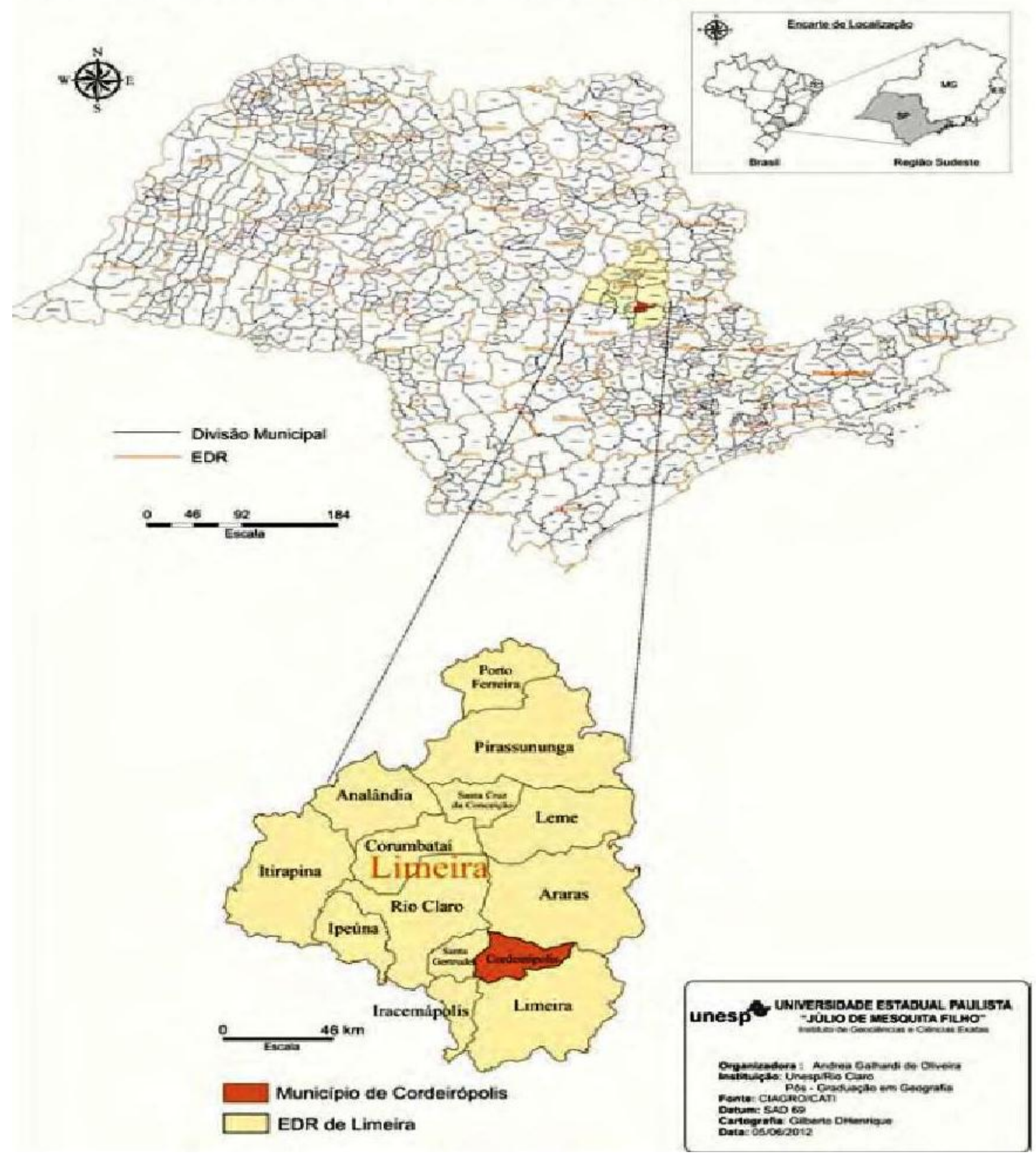


Assim, tomando como referência o contexto urbano dos pequenos municípios do estado, em especial aqueles localizados na Região Político Administrativa de Campinas, ${ }^{1}$ este estudo é parte do trabalho de pós-doutorado que busca investigar os processos determinados pelo conjunto de ações socioespaciais, públicas e privadas que impulsionaram, isto é, promoveram dinâmicas no território urbano.

No cenário regional mencionado, os municípios conformaram e evoluíram suas tramas urbano-rurais, em especial a partir do período final século XVIII, pautados na exploração econômica da terra, inicialmente como base produtiva pautada no setor agrário e posteriormente como mercadoria de valoração patrimonial das classes sociais dominantes.

A propriedade da terra funcionou ainda como instrumento de manutenção e extensão de poder, fator inicialmente atrelado aos interesses da coroa portuguesa - objetivando a ocupação e garantia de posse do território brasileiro - e posteriormente como instrumento de constituição e ascensão ao governo imperial.

Passados pouco mais de dois séculos, a conformação da rede de municípios organizada no entorno de Campinas - interligada por cadeias produtivas e interesses econômicos - contextualizou-se desde a sua origem pela formação e expansão das urbes atreladas ao capital, fatores que vieram impulsionar a região a se transformar no terceiro parque industrial do país a partir das décadas de 1980 e 1990 do século XX.

No período presente, aglomerações formadas pela proximidade - por vezes continuidade - entre malhas urbanas de algumas cidades, indicam processos de conurbação, onde estão representadas características socioespaciais similares entre as mesmas, pautadas em especial nos arranjos produtivos e nos modos de apropriação do solo.

Algumas destas ocorrências encontram-se inseridas na Metrópole Campineira, composta por vinte municípios ${ }^{2}$ e também do Aglomerado Urbano de Piracicaba, ${ }^{3}$ constituído por vinte e dois.

São exemplares as relações de proximidade entre as cidades de Americana e Santa Bárbara D'oeste, Campinas, Hortolândia e Sumaré, bem como os processos de interação produtiva decorrentes entre Cordeirópolis, Limeira, Rio Claro, Iracemápolis, Santa Gertrudes e Araras, que abrigam atividades complementares dos ramos industriais metal/mecânico e cerâmico.

Assim, considerando a inserção das cidades de pequeno porte na Região Administrativa de Campinas, os estudos e pesquisas ora propostos são conduzidos no sentido de coletar informações, estabelecer os modos como se configuraram as dinâmicas no socioespaço e apontar possíveis soluções atreladas aos estudos das cidades criativas, em um recorte urbano, objeto de estudos representado pela área da Estação Ferroviária da cidade de Cordeirópolis, inserida na composição regional supramencionada, leste do Estado de São Paulo.

Abordam-se de modo a compor um entendimento geral dos processos de ocupação do solo na área da Estação Ferroviária, as ações públicas e privadas, pesquisando acerca das primeiras, os eventuais dispositivos legais e políticas de gestão, com suas ramificações, em especial aquelas relacionadas à dinâmica aplicada para a ocupação fundiária do solo na cidade e às questões do transporte ferroviário.

Na contextualização das atividades de caráter privado concentrou-se na evolução dos setores produtivos no município, em especial a indústria cerâmica, que impulsionou a produção imobiliária voltada ao atendimento das necessidades habitacionais dos trabalhadores.

\footnotetext{
${ }^{1}$ A Região Político Administrativa de Campinas está dividida nas seguintes Regiões de Governo: Bragança Paulista, Campinas, Jundiaí, Limeira, Piracicaba, Rio Claro e São João da Boa Vista.

${ }^{2}$ Região Metropolitana formada pelos municípios de Americana, Arthur Nogueira, Campinas, Cosmópolis, Engenheiro Coelho, Holambra, Hortolândia, Jaguariúna, Indaiatuba, Itatiba, Monte Mor, Nova Odessa, Paulínia, Pedreira, Santa Bárbara D’Oeste, Santo Antonio da Posse, Sumaré, Valinhos, Vinhedo e Morungaba.

${ }^{3}$ Águas de São Pedro, Analândia, Araras, Capivari, Charqueada, Conchal, Cordeirópolis, Corumbataí, Elias Fausto, Ipeúna, Iracemápolis, Leme, Limeira, Mombuca, Piracicaba, Rafard, Rio Claro, Rio das Pedras, Saltinho, Santa Gertrudes, Santa Maria da Serra e São Pedro.
} 


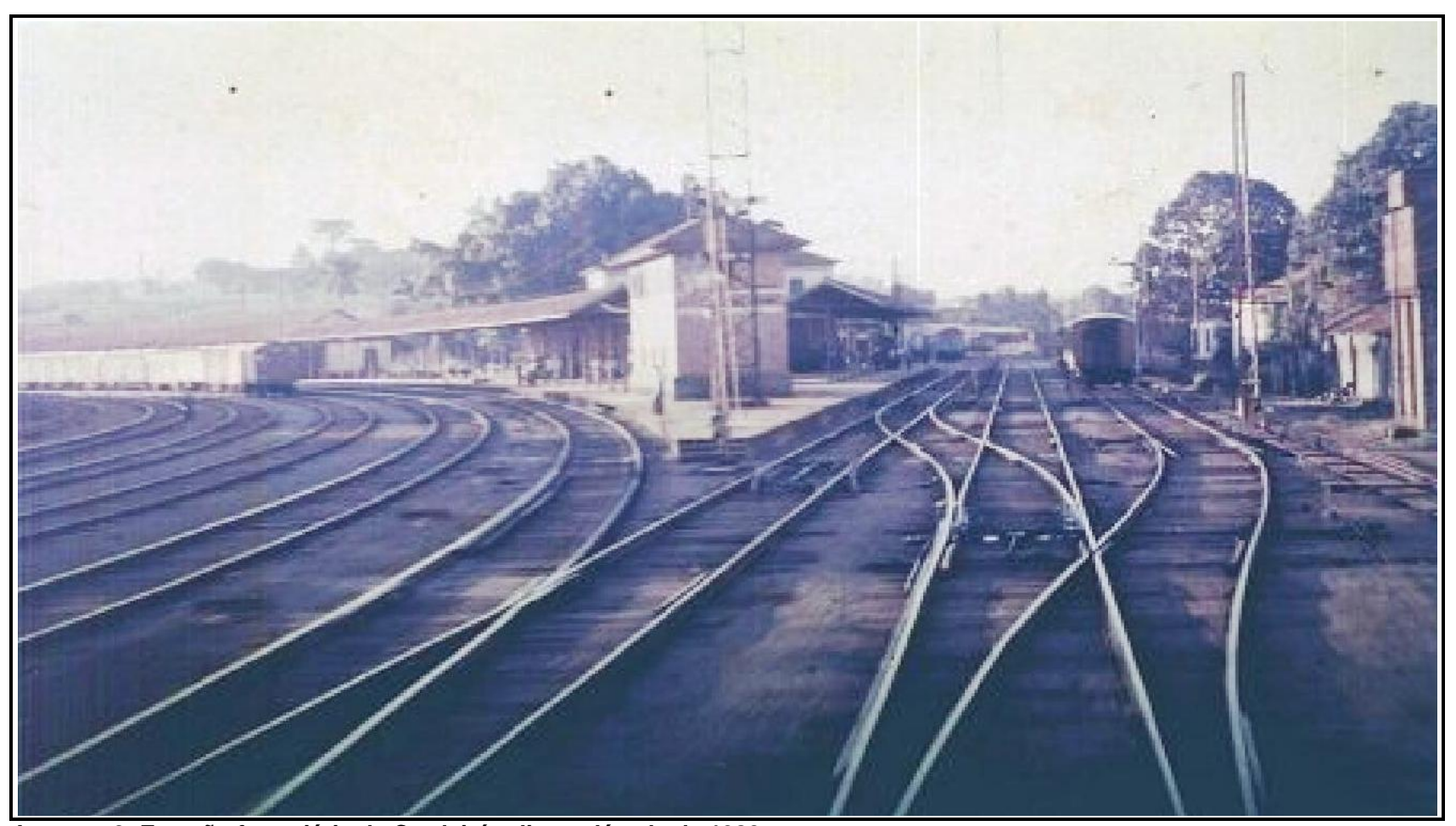

Imagem 2: Estação ferroviária de Cordeirópolis na década de 1980.

(Pascon, 2013)

Importa destacar que a abordagem mencionada concentrou-se no período final da década de 1980, até o início deste segundo decênio do século XXI, buscando estabelecer contribuição ao estudo de proposta e soluções criativas para a dinâmica do socioespaço, sua história e suas resultantes para as comunidades das pequenas cidades paulistas.

\section{O CONCEITO CRIATIVO}

Foram tratadas neste estudo, as ocorrências resultantes da dinâmica socioespacial em Cordeirópolis e as consequentemente propostas para a mitigação de problemas e aplicação de instrumentos de gestão, atrelados ao conceito de cidades criativas, buscando ampliar os estudos neste campo de pesquisas pois, como apontado por Landry: "Uma cidade criativa estimula a inserção de uma cultura de criatividade, no modo como se participa da cidade. Ao incentivar a criatividade e legitimar o uso da imaginação nas esferas pública, privada e da sociedade civil, amplia-se o conjunto de ideias de soluções potenciais para qualquer problema urbano. Esse é o pensamento divergente, que gera múltiplas opções e deve ser alinhado ao pensamento convergente, que fecha as possibilidades, a partir das quais as inovações urbanas que se mostraram viáveis podem emergir. Uma cidade criativa demanda infraestruturas que vão além do hardware - edifícios,ruas ou saneamento. Uma infraestrutura criativa é uma combinação de hard e soft, incluindo a infraestrutura mental, o modo como a cidade lida com oportunidades e problemas; as condições ambientais que ela cria para gerar um ambiente e os dispositivos que fomenta para isso, por meio de incentivos e estruturas regulatórias. Para ser criativa, a infraestrutura soft da cidade precisa incluir: força de trabalho altamente capacitada e flexível; pensadores, criadores e implementadores dinâmicos, já que a criatividade não se refere apenas a ter ideias; infraestrutura intelectual ampla, formal e informal - mesmo assim, muitas universidades que parecem fábricas com linhas de produção não ajudam; ser capaz de dar vazão a personalidades diferentes; comunicação e redes fortes, internamente e com o mundo exterior, bem como uma cultura geral de empreendedorismo, seja com fins sociais ou econômicos" (Landry, 2013:13-14).

Este autor destacou também que um aproveitamento máximo da criatividade existente no lugar deve ser pautar no conhecimento amplo do desenvolvimento de sua história e cultura: "Levar a cultura em consideração nos ajuda a entender de onde um lugar vem, por que ele está como está e como pode criar seu futuro, por meio de seu potencial. Esses recursos culturais são a matéria-prima da cidade e sua base de valores; seus ativos, substituindo o carvão, o aço ou o ouro" (Landry, 2013:15). 
Deste modo o conceito de criatividade foi utilizado como instrumento para explorar os recursos disponíveis no plano local e está atrelado neste estudo à questão histórica e cultural da evolução urbana de Cordeirópolis, sem perder de vista as atividades produtivas, tendo como foco a Área da Estação.

Procurou-se, caracterizar e integrar fatores como a criatividade, a cultura e a questão dos arranjos produtivos locais, de modo a propor ferramentas que venham contribuir com a construção de uma metodologia voltada ao reconhecimento, gestão e exploração dos recursos locais.

Como observado por Landry (2013:15), esta cultura deve ser considerada ao estabelecer os critérios e técnicas "do planejamento e do desenvolvimento urbanos, ao invés de ser vista como um acessório marginal a ser considerado, uma vez que as questões importantes de planejamento, como habitação, transporte ou ocupação do solo, estiverem resolvidas."

Assim, as tratativas propostas buscaram contemplar as condicionantes culturais e também as questões produtivas locais, dentro do contexto do ramo cerâmico de cunho artesanal existente no município, buscando apresentar propostas para a evolução da economia criativa e justiça social, pautadas no planejamento urbano sustentável e atreladas ao incentivo da preservação da história e cultura locais.

Importa ainda apontar que a presente pesquisa, pautada neste exemplar da conformação socioespacial urbana na Região Administrativa de Campinas, enquanto conjunto detentor de municípios interligados no campo físico e econômico, como Limeira, Rio Claro, Santa Gertrudes, Cordeirópolis e outras urbanizações de portes pequeno e médio do sudeste brasileiro, esta contextualizada por relações socioespaciais decorrentes nos contextos local, regional e estadual, bem como no âmbito federal.

Tendo em vista as observações sobre a ocupação do solo no objeto de estudos ora proposto, destacam-se como áreas de interesse os impactos desta ocorrência na vida comunitária, influenciada na última década pela ampliação espacial e populacional, estas pautadas na evolução das atividades produtivas do setor cerâmico na cidade de Cordeirópolis.

Deste modo, objetivando-se uma investigação mais detalhada para a elaboração de propostas de cunho criativo no local, estabeleceram-se algumas relações e processos desta dinâmica urbana, entendendo-as como problemas para elucidação da pesquisa e como procedimento de análise, em especial aquelas ligadas a evolução do setor produtivo e as atividades ferroviárias.

Deste modo, o objetivo central do estudo sobre a Estação de Cordeirópolis esta em identificar as alternativas viáveis para a evolução da economia criativa e justiça social na cidade, estas pautadas no planejamento urbano sustentável e atrelado ao incentivo da preservação da história e cultural locais.

\section{DINÂMICA ESPACIAL NAS CIDADES}

Como observado por Howkins (2011:128), "Imagine andar por uma cidade; em alguns lugares é um prazer, em outros um aborrecimento. É muito melhor quando há um conjunto de pessoas e atividades diferentes, em vários espaços e locais".

Como apontado por Souza (2003), no âmbito dos cenários urbanos brasileiros, desejar e propor, como muito se fez no urbanismo tecnicista ainda presente em nossas cidades, são verbos distantes da realidade atual econômica, social e política, onde é crescente a exigência da participação dos variados grupos que compõe o conjunto da comunidade.

Entende-se desta maneira que as urbanizações presentes necessitam de planejamento atrelado à realidade pautados na análise do cenário local e focados em eficiência, eficácia e resultados que possam garantir estas resultantes positivas aos espaços inertes no plano das cidades.

Assim, a cidade real deve acompanhar os anseios do cidadão, todavia, dever permear suas necessidades de modo a garantir que cada ação ou proposta elaborada pelo poder público venha a trazer benefícios diretos e indiretos à população, bem como garantir que as estratégias de melhoria, presentes nas propostas, sejam implementadas.

Tais estratégias devem ser o alvo para a aplicação das políticas de revitalização e reestruturação do espaço, visando solucionar os problemas urbanos e trazer benefícios para toda a comunidade. 
Deste modo, seria possível buscar a garantia das condições de integração e uso espacial as áreas degradadas e sem uso definido (em inércia espacial), estas enquanto objetos de consumo, por exemplo, imputando-Ihes dinâmicas que as socializem e tornem estes sítios urbanos eventualmente estagnados, integrados e funcionais ao contexto da cidade.

Considerando o exposto com relação aos espaços em desuso, ou de uso incompatível com determinadas porções das cidades, há que se apontar que tais áreas são identificadas em praticamente todos os cenários urbanos brasileiros, sendo passíveis - aplicados os instrumentos disponíveis no arcabouço técnico e legal existente - da promoção de consumo do espaço pautado em um planejamento estratégico, este voltado, por exemplo, as questões da criatividade e valorização da cultura local.

Inserindo nestes locais propostas desenvolvidas por intermédio da discussão e participação dos diversos atores sociais, como poder público, associações de classes, associações de moradores e demais agentes presentes na sociedade, com projetos que venham a beneficiar toda a cidade, é possível recuperar e ordenar as dinâmicas destes locais, de modo a garantir seu desenvolvimento e torná-los objetos de uso e consumo comuns.

Estes ideais, aplicados aos estudos de áreas decadentes e deterioradas espacial e socialmente, por exemplo, poderiam trazer novamente à atividade extensas áreas próximas às ferrovias em cidades paulistas interioranas como Cordeirópolis, Limeira e Rio Claro, incentivando seu uso pela comunidade com atividades que atendessem as disposições das leis de uso e ocupação do solo e necessidades locais.

Implantar nestes pontos das cidades atividades que não tenham exigências e incompatibilidades atreladas a sua localização estratégica distante das áreas centrais, que sejam suplementares às necessidades da população local e de toda a comunidade, ou sirvam à estratégia e/ou ao marketing voltado à promoção do município e incentivo à cultura, ao emprego e à geração de renda.

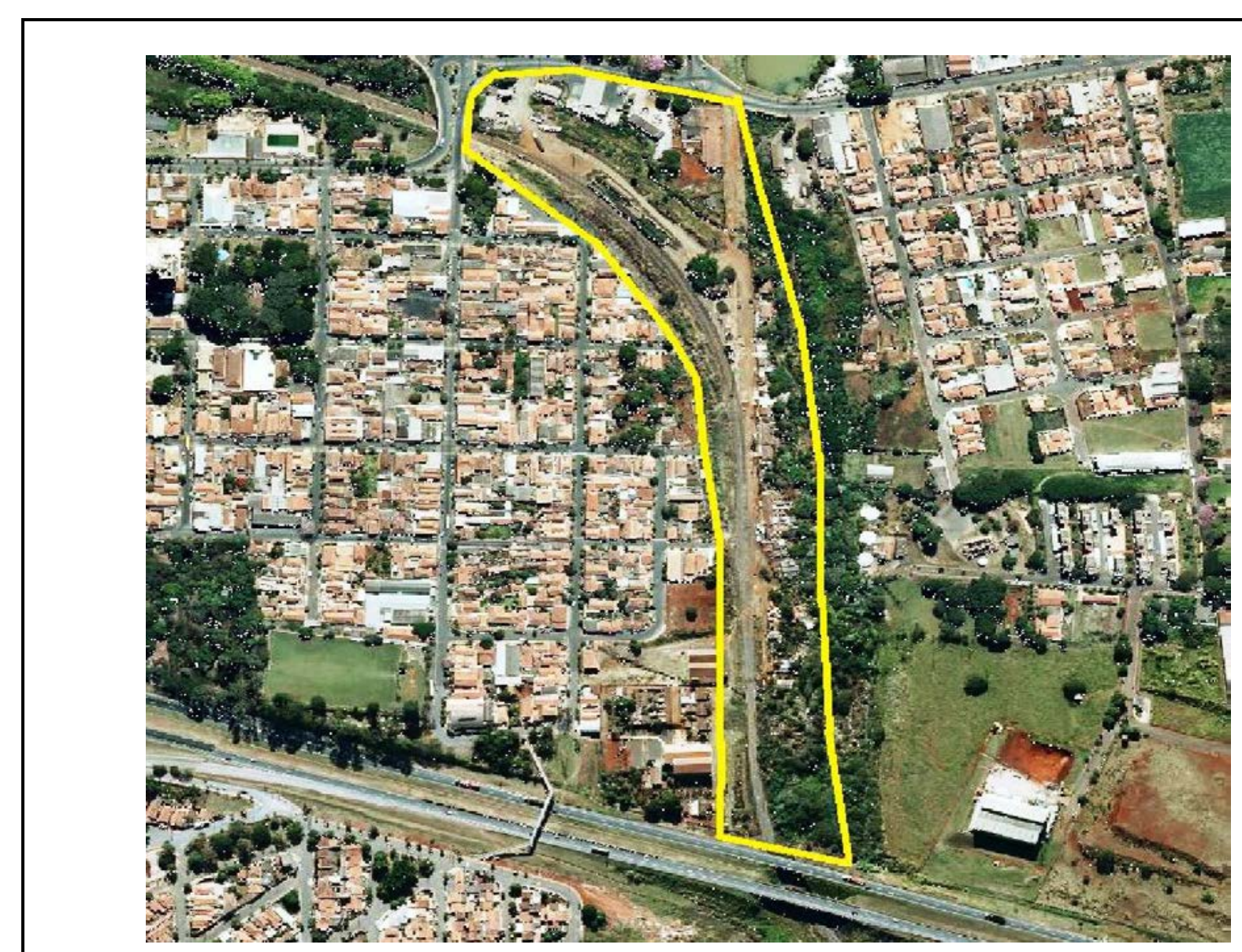

Imagem 3: Pátio da Estação ferroviária de Cordeirópolis.

(Sanches, 2014) 
Quanto às áreas estagnadas de interesse do patrimônio local, deve-se apontar para o cuidado em sua caracterização quanto à importância histórica e cultural, visando planejar de modo técnico e político o incentivo dinâmico ao suo, promovendo dentro do escopo da preservação, as melhorias de suas condições estruturais.

Também importa atrelar os pontos em inércia no tecido das cidades em questão, aos ideais de melhoria na oferta e uso do transporte urbano, tanto de pedestres e ciclistas, quanto de motoristas, objetivando ampliar as condições de segurança - notadamente no período noturno - dinamizando, por exemplo as iniciativas comerciais e de gestão empresarial e política dos sistemas apontados.

Analogamente entende-se que propostas para áreas nas cidades em processos de inércia e deterioração carecem em especial do planejamento quanto a elaboração de suas estratégias de ocupação e retomada, voltadas à requalificação e ao uso.

Assim, tais locais urbanos poderiam abrigar atividades compatíveis com sua infraestrutura e potencial para absorção das mesmas, procurando iniciativas pautadas em se desenvolver o consumo dinâmico e evolutivo, no atendimento as necessidades que tragam benefícios urbanos de modo pontual, com resultantes também para os panoramas externos regional e global.

A existência nestas áreas de ações no ramo comercial de varejo por exemplo, bem como a presença de casas noturnas e restaurantes, pode sinalizar para a valorização das mesmas enquanto alavancas para o direcionamento das estratégias de planejamento local de desenvolvimento destas atividades.

Assim, se cabe à cidade e aos cidadãos, liderados pelos seus representantes, opinar sobre esta ou aquela solução ao consumo do espaço, então há também de se imaginar que todos os dias em nossas urbanizações, um único cidadão ou pequeno grupo de pessoas tem tomado para si decisões acerca desta apropriação, o que em tempo futuro torna-o restrito para toda uma sociedade.

Tal prática está tanto numa simples invasão de terreno ou edificação abandonada, quanto na ocupação e transformação de um complexo industrial em um centro de compras.

Tem-se assim estabelecida a questão pautada na inércia e estagnação do socioespaço local, e nos modos de promover desenvolvimento às áreas urbanas identificadas nestes processos, por intermédio de dinâmicas que permitam toda a sociedade se beneficiar direta ou indiretamente do processo.

A resposta pode estar na estratégia e na participação social, decidindo uma das necessidades primordiais do socioespaço urbano: a dinâmica.

\section{EXPANSÃO DE PROBLEMAS URBANOS E OCUPAÇÃO ESPACIAL}

Os principais problemas observados no município de Cordeirópolis passam pela condição de pujança econômica apresentada pela localidade nas últimas décadas.

A evolução de seu campo industrial, atrelada a condição logística da cidade trouxeram questões atreladas à mobilidade urbana e à infraestrutura de modo global, estas ladeadas, como comentado anteriormente à problemática habitacional.

As políticas aplicadas no plano municipal e o planejamento urbano não se mostraram capazes de solucionar os principais acontecimentos negativos e ocorrências presentes na evolução urbana, embora medidas como a elaboração e instalação do Plano Diretor tenham estabelecido caminhos para as possíveis soluções.

Com relação à mobilidade urbana, em especial com relação ao sistema viário, são visíveis os problemas relacionados ao trânsito e aos transportes, marcados pela ineficácia da sinalização, precariedade das calçadas, inadequação de equipamentos ligados à acessibilidade, problemas ladeados pela ausência de estudos relacionados ao tráfego de veículos e pedestres, bem como a uma baixa capacidade de suporte das vias.

Também é notável a inexistência de ciclovias e o precário funcionamento das linhas de transporte público aponta-se que o município, embora de pequeno porte, tem distritos industriais, por exemplo, localizados a 
uma distância entre cinco e oito quilômetros da malha urbana - que poderiam auxiliar na redução de veículos particulares nas vias.

Outro fator preponderante no quesito em questão trata do transporte de matéria prima e produtos da indústria cerâmica, que dada a presença de unidades distribuídas em todo o entorno da urbanização promovem a circulação contínua e desordenada de veículos pesados pela malha viária, tornando o trânsito local lento e caótico.

Segundo a UFSCar (2007), caracterizava - e que ainda ocorre - o sistema viário de Cordeirópolis a inexistente hierarquização das vias municipais, com exceção às rodovias Anhanguera, Bandeirantes e Washington Luis, estas que serviam como opções para o trânsito rápido.

Cabe ainda apontar que a circulação de veículos de transporte de matéria prima cerâmica - composta essencialmente por argila seca - promove a suspensão de partículas sólidas no ar.

Esta informação vivenciada no cotidiano da cidade se confirma no conteúdo do relatório "Qualidade do $\mathrm{Ar}$ no Estado de São Paulo 2014", elaborado pela Companhia Ambiental do Estado de São Paulo (CETESB) ${ }^{4}$ onde está indicado que embora ainda em níveis pouco abaixo do considerado crítico, o problema se efetiva em Cordeirópolis.

Com relação aos problemas ambientais, cabe destacar que a retirada de matéria prima do solo e o armazenamento do material destinado à produção cerâmica, também são processos preocupantes no contexto local.

A degradação ocasionada quando da retirada da argila das jazidas, que têm como resultantes as cavas, promovem o surgimento de verdadeiras crateras a céu aberto, sendo algumas com profundidade superior a quarenta metros, que acabam por ser transformadas, após a finalizada a exploração da matéria prima e devido a presença de água do lençol freático, em lagoas bastante profundas e sem finalidade específica.

Dentre outros problemas contribuem para alterações no nível de água no subsolo, diminuição das áreas agrícolas e remoção de solo fértil, além de se tornarem áreas obsoletas ao uso produtivo do solo.

O armazenamento do material removido das cavas de argila, utilizado para a produção cerâmica - em seu preparo como matéria básica de manufatura- configura os pátios de secagem, que são espaços de dimensões elevadas, localizados tanto no interior, quanto em áreas por vezes afastadas das indústrias, áreas o material é disposto em montes, com o objetivo de estabilizar a presença de água no mesmo.

A partir destes pátios e devido a ação do vento, partículas sólidas se espalham no ar e acabam por se instalar nas coberturas dos imóveis, áreas livres, vias e espaços urbanos, normalmente se dissipando com as chuvas, o que promove uma série de problemas de saúde a população, em especial nos meses mais frios e secos do ano

Também é considerável pela poluição produzida na indústria cerâmica, a possibilidade de contaminação das represas que fazem o abastecimento de água da cidade e da produção agrícola na zona rural.

Outro problema enfrentado pelo município está na questão da água para abastecimento, dentre outros a questão do custo para sua produção, como apontou Lacerda (2015 b), em reportagem onde observa que a escassez da matéria bruta está promovendo o encarecimento do produto.

Importa destacar a este respeito que a principal represa - a do Bairro do Cascalho - que abastecia a cidade foi atingida no biênio 2014 a 2015 por grave escoamento de sua reserva, ocasionado por fatores como a baixa precipitação neste período, incrementado pela carência com relação ao planejamento preventivo de fontes alternativas à captação e ao consumo nos períodos anteriores, bem como de soluções efetivas de longo prazo nos dez anos passados, que pudessem mitigar a situação em períodos de longa estiagem onde a reserva não fosse suficiente.

Também contribuiu para a questão da represa do Cascalho o desmatamento e a presença de propriedades em seu entorno e na cabeceira, onde estão suas nascentes, que se utilizam da água antes que a mesma

\footnotetext{
${ }^{4}$ C.f. CETESB, 2014.
} 
abasteça o manancial e ainda reservam água para utilização na produção rural, sem estudos e discussões por parte das autoridades municipais e estaduais.

Pode ainda ser apontado como um problema urbano a questão do esgoto no município. Já em 2005, os estudos de Levighin, apontaram que em amostras de água e solo (em forma de lodo) coletadas em uma das fontes de abastecimento, a Represa Santa Marina, as margens da Rodovia Washington Luis, a concentração de sódio estava acima do limite indicado, o que poderia indicar ter sido elevado pelo esgoto domiciliar e industrial e pelas características geológicas do local.

A autora apontou ainda que no entorno da Santa Marina havia produção de cana-de-açúcar, além de vegetação rasteira e poucos vestígios de mata ciliar.

Lacerda (2015 a), em reportagem para o jornal Gazeta de Limeira apontou que segundo o Serviço Autônomo de Água e Esgoto de Cordeirópolis (SAAE), autarquia responsável pela rede, o município produz $1350 \mathrm{~kg}$ de demanda bioquímica de oxigênio (DBO) por dia ${ }^{5}$.

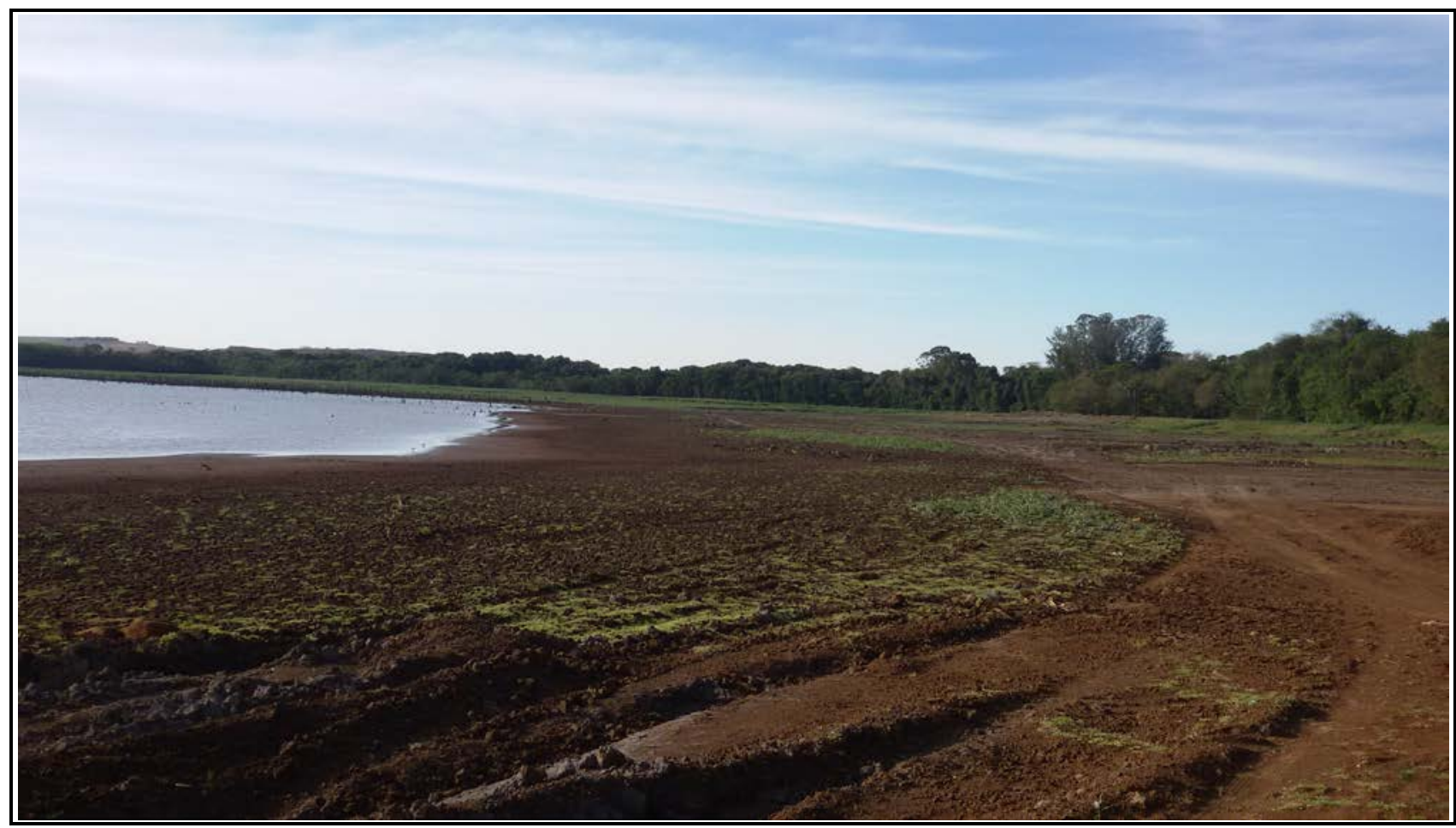

Imagem 4: Represa do Cascalho com nível abaixo do normal em 2014.

(Elaboração do autor, 2015)

Conforme esta mesma autora, atualmente estão se iniciando as obras de execução da estação de tratamento de esgotos a jusante do Ribeirão Tatu, curso hídrico que recebe a maior parcela do montante de esgotos produzido pelo município e deverá reduzir o problema local, com expectativa que o volume seja minimizado para $100 \mathrm{~kg}$ de DBO por dia.

Outra questão considerável com relação aos principais problemas urbanos está centrada na preservação e requalificação no âmbito do planejamento urbano municipal, tem como premissa a recuperação de áreas abandonadas e semidestruídas da cidade, como por exemplo a área do "Páteo da Estação" (FIGURA 22), que abriga além da antiga Gare, um conjunto de edificações residenciais e institucionais, como um teatro municipal.

Destaca-se que tal espaço em meio a malha urbana, divide a mesma em porções distintas e impossibilita a ocupação do solo dentro dos padrões sustentáveis e de qualidade de vida pretendidos para a população local e do entorno devido à degradação socioespacial em que se encontra, pautada no uso irregular do solo, invasões e atos ligados ao consumo e tráfico de entorpecentes. 
Dentro das propostas, destacando-se as preocupações com o planejamento urbano, cabe apontar para a necessária premissa de melhorar a qualidade de vida da população ali residente e no entorno e, manter e preservar sua história, por intermédio da aplicação de conceitos de planejamento urbano e projetos de recuperação e definição de atividades para os prédios da antiga Estação, bem como a revitalização de seu entorno com praças e áreas verdes e a recuperação das áreas de preservação ambiental em seu entorno.

Entende-se deste modo que com a revitalização da Estação Ferroviária, o município poderia transformar a área em um complexo educacional, cultural, comercial e turístico, oferecendo em um primeiro momento às famílias que invadiram a área, assistência educacional, voltada à melhoria profissional e das condições de saúde, estas focadas na obtenção e geração de emprego e renda.

Tal objetivo está apoiado na intenção de oferecer ao cidadão, condições de sobrevivência e qualidade de vida, que poderão conduzi-los a habitação em outros locais adequados as suas necessidades, abrindo espaços na área da estação, para que a sociedade possa efetivar o atendimento às necessidades de outros munícipes que estejam em necessidade e a toda a coletividade.

\section{EXPANSÃO DA CULTURA CRIATIVA}

A questão da aplicação dos conceitos de economia criativa, tendo como foco a Estação Ferroviária de Cordeirópolis passa como explicitado no decorrer deste estudo, por fatores ligados a questão da preservação do patrimônio histórico e cultural local, ao planejamento urbano e, em especial à gestão urbana.

A situação de degradação - gradativa e silenciosa - esconde problemas urbanos como a segregação, a subhabitação, a violência e a desvalorização humana e socioespacial, impondo condições de miséria aos ocupantes daquela porção do território urbano.

Entende-se que sob a tutela da economia e das cidades criativas, estas focadas na utilização da criatividade presente no local como instrumento de transpasse dos problemas socioespaciais, poder-se-ia mitigar e solucionar a maioria dos conflitos ora representados naquela área da cidade.

Utilizando-se da capacitação dos moradores como ferramenta de inclusão e ampliando as oportunidades locais de geração de emprego e renda, apoiando estas iniciativas no regate da dignidade e da cidadania, seria possível diminuir distâncias e aproximar diferenças no socioespaço de Cordeirópolis.

Também se observa que além de espaços voltados à formação como biblioteca e oficinas de capacitação, e locais de estudo e trabalho, seria possível abrigar ali serviços públicos - gerando economia para a municipalidade em especial relacionada aos aluguéis de edificações para instalar repartições - e privados resolvendo problemas como ambulantes em locais inadequados e espaços para ovas atividades.

Nota-se que incentivando a criatividade, esta se torna um instrumento capaz de fomentar a expansão de oportunidades não somente locais, como por todo o município, entretanto cabe apontar que a cidade criativa deve ser liderada pela gestão e esta estar voltada a promoção socioespacial das melhorias urbanas, como observou Iversen:"Também nos parece importante discutir o papel dos governos locais no desenvolvimento de uma política cultural e da economia criativa, que favoreça a diversidade, a criação de empregos, o desenvolvimento econômico, a regeneração urbana e o investimento em infraestrutura criativa e em design" (Iversen, 2013: 131).

Estes fatores integrados e parte de um planejamento estratégico elaborado pela gestão local, poderiam se tornar atrativos para negócios diferenciados em um futuro não muito distante, pautado em uma futura adequação das atividades realizadas no espaço da Estação, direcionadas para ramos de interesse do pensamento voltado ao desenvolvimento criativo do município, bem como pautados ainda em outras questões estruturais, como definiu a autora:"As cidades devem se preparar e gerar vantagens pelo uso de transportes modernos, atraentes e favoráveis ao ambiente, o que também torna os negócios mais atraentes. O planejamento de longo prazo inclui clima, energia, meio ambiente e também transporte, que foi incorporado na parte de uso do solo, no Plano Diretor. É preciso coordenar os vários planos. Bom transporte público e uma rede de ciclovias, que levem e tragam as pessoas do trabalho, com conforto e eficácia, aumentam a atratividade do trabalho em Bergen. Também devemos olhar além dos limites de nossa cidade e colaborar com nossos vizinhos" (Iversen, 2013:135). 
Também os conceitos de formação e educação oferecidos poderiam deste modo estar concentrados em capacitar os interessados em áreas do conhecimento - algumas atreladas à história e cultura local - ainda pouco desenvolvidas no plano local, proporcionando formação de mão de obra atrativa em ramos como informática, preservação ambiental e cultura.

Neste ínterim, como apontado por Newbigin, tendo como parâmetros a história e a cultura local, a "economia criativa", se diferencia das demais áreas econômicas em especial por intermédio da "complexa herança cultural": "[...] a origem da economia criativa, como se chama normalmente, se deu quando as antigas tradições do trabalho cultural e industrial - design, produção, decoração e representação começaram a ter vínculos com uma gama mais ampla de atividades produtivas modernas -a publicidade, o design de roupa, o desenho gráfico e a mídia de imagens em movimento - e, mais importante ainda, quando começaram a ter maior abrangência pelo poder da tecnologia digital. é o que diferença a economia criativa de qualquer outro setor da economia" (Newbigin, 2010:13).

O autor comentou ainda que no decorrer de parte significativa da história da humanidade, esta dinâmica cultural do processo criativo não ocorreu atrelada à economia, pois englobava normalmente atividades exercidas pelas pessoas de modo não profissional, como lazer ou após a aposentadoria, entretanto no período recente tais ações são consideradas "expressões do valor cultural e econômico"(Newbigin, 2010:13).

Newbigin em sua análise sugeriu ainda que:"Além do seu valor de troca, (que é o estágio final para que os bens e serviços encontrem o seu nível de preço ótimo no mercado) e seu valor funcional (determinado pela maneira como se usam no dia a dia), a maioria dos produtos e serviços das indústrias criativas têm um 'valor expressivo', um significado cultural que pouco ou nada tem a ver com os custos da sua produção ou utilidades. Por exemplo, uma bolsa da alta moda, um filme, uma marca bem-sucedida, um ícone religioso ou um novo design conceitual" (Newbigin, 2010:13).

Outro fator importante está na questão da recuperação da área da Estação Ferroviária, enquanto objeto integrante da cultura e do socioespaço local.

Deste modo entende-se que a expansão deste costume passa antes de qualquer fator pela vontade do poder público local no incentivar e promover a requalificação da área em questão, buscando parcerias nas esferas superiores de poder.

Também é possível posteriormente ao processo de mencionado de recuperação do local, a concessão de incentivos fiscais, mitigação de entraves legais e administrativos, e demais processos atrativos à iniciativa privada, que possa estabelecer programas governamentais voltados à manutenção e melhoria do ambiente local.

Com esta atuação, estariam programadas e planejadas ações voltadas a garantir maiores chances na atração de investidores e fixação do ideal de funcionamento do complexo de edifícios e, em especial da produção de atividades com foco criativo.

Entende-se desta forma que a decisão do poder público local precisa estar pautada na justa apreciação do bem público, na transparência de atitudes e foco na recuperação do socioespaço e da qualidade de vida na cidade.

A este respeito, em seus estudos sobre Brownfields ${ }^{6}$, Vasques comentou:"[...] uma política que vise auxílio para os programas de refuncionalização de brownfields deve contar com o reconhecimento do interesse público na questão, deve estar aberta à participação dos poderes públicos e da iniciativa privada, conceder crédito para a limpeza das áreas mais urgentes, e instituir parcerias criando um clima de cooperação entre os agentes. As comunidades devem ser vistas como sócios, ao mesmo tempo em que os governos locais devem estar dispostos a envolver as comunidades e a patrocinar a refuncionalização, possibilitando assim, maiores chances de obter sucesso. Atualmente, os governos vêm dando prioridade à recuperação dos centros históricos e seus patrimônios, negligenciando antigas áreas não centrais. Algumas áreas próximas

\footnotetext{
${ }^{6} \mathrm{Na}$ última década, o redesenvolvimento de áreas industriais abandonadas vem sendo uma ação prioritária por parte do governo federal, estadual, municipal e de algumas comunidades norte-americanas. Nos Estados Unidos, estas antigas instalações industriais abandonadas são conhecidas como brownfields e ocupam bairros ou cidades inteiras, principalmente no nordeste e centro-oeste americano, onde a indústria estava localizada. (C.F. Vasques, 2005:.2)
} 
ao centro apresentam, quase sempre, déficits de acessibilidade, visibilidade e de equipamentos e serviços que imprimam neles funções centrais" (Vasques, 2005:50).

Um exemplo atual da tentativa de requalificação urbana pautada no processo criativo é a cidade de Detroit, nos Estados Unidos, conhecida mundialmente a partir da década de 1950, por produzir aproximadamente cinquenta por cento da produção de veículos e que segundo Trevisan (2014) tinha àquele período cerca de dois milhões de habitantes, figurando como a quarta maior cidade americana.

Segundo a autora, entre as décadas de 1970 e 2010 a cidade presenciou - em especial dada a fatores como a concorrência da indústria japonesa de veículos no mercado norte americano - brusca queda em sua participação nos mercados local e mundial produtor de veículos e também retração populacional.

Trevisan (2014) comentou que atualmente a cidade conta com 685 mil habitantes, e cerca de vinte por cento das indústrias locais: "[...] O desequilíbrio financeiro foi agravado por alguns governos desastrosos e outros corruptos, que contribuíram para empurrar Detroit à insolvência, com uma dívida de US\$ 18 bilhões. No dia 3 de dezembro de 2013, ela se tornou a maior cidade americana a entrar em concordata, dando início a um processo de negociação com credores que será acompanhado de perto por municípios como Chicago e Los Angeles, que enfrentam problemas semelhantes em seus deficitários fundos de pensão. As estatísticas apresentadas no pedido de concordata revelam uma cidade incapaz de prover serviços básicos aos moradores, imersos em alguns dos piores indicadores sociais dos Estados Unidos. O porcentual de pessoas que vivem abaixo da linha da pobreza é de $36 \%$, mais que o dobro da média de $15,7 \%$ do Estado de Michigan. Apenas $12,2 \%$ da população concluiu a faculdade, comparado a $25,3 \%$ no Estado. O índice de desemprego é de $16,2 \%$, quase dez pontos porcentuais acima dos $7 \%$ registrados nacionalmente" (Trevisan, 2014:1).

A saída para a cidade parece estar ligada a economia criativa, atrelada à atração de empresas do ramo de serviços, que passam a ocupar as áreas abandonadas da área central e dos setores industriais.

Atualmente, planeja-se o processo de recuperação, pautado em especial no custo acessível de imóveis de dimensões elevadas, por exemplo, antigos barracões industriais, considerados Brownfields.

Segundo Trevisan (2014) algumas empresas do ramo de tecnologia como o Twitter e o Google, gigantes das vendas pela internet como a Amazon, além de empresas de publicidade e mesmo escritórios de arquitetura, estão tomando posse dos antigos edifícios, tanto atraídas pelo baixo custo dos imóveis, quanto pelo ideal proveniente do cenário de recuperação.

A autora comentou ainda que a Rock Ventures, holding que tem entre suas subsidiárias a Quicken Loans, companhia americana de concessão de crédito imobiliário pela internet - esta com cerca de doze mil funcionários trabalhando em Detroit - investiu US\$1,3 bilhão nos últimos três anos na compra de quarenta e cinco imóveis no centro de Detroit, incentivando um movimento de revitalização que está atraindo outros empreendimentos, como por exemplo, várias startups no ramo de tecnologia.

Com relação à tipologia dos trabalhos que podem ser desenvolvidos de modo criativo, trabalho elaborado pela Bop Consulting (2010), com o apoio do British Council, apresenta um gráfico dividindo as indústrias criativas em quatro grandes áreas - serviços criativos, conteúdos criativos, experiências criativas e originais criativos - e demonstrando processos de interseção entre elas, distribuindo as diversas atividades nestas grandes áreas ou em suas interseções.

Segundo este estudo não é possível estabelecer uma "definição padrão de indústrias criativas, pois cada país adota uma definição diferente de acordo com suas necessidades" (Bop Consulting, 2010:36).

Assim, faz-se importante que exista uma reflexão e estudo pormenorizado e integrado à realidade das atividades, bem como da cultura e do socioespaço local, trabalho este realizado por especialistas de áreas diversas, que levem em consideração fatores e especificidades de cada localidade, desde o escopo municipal até o regional e nacional ${ }^{7}$.

\footnotetext{
${ }^{7}$ C.f. Bop Consulting, 2010:36.
} 


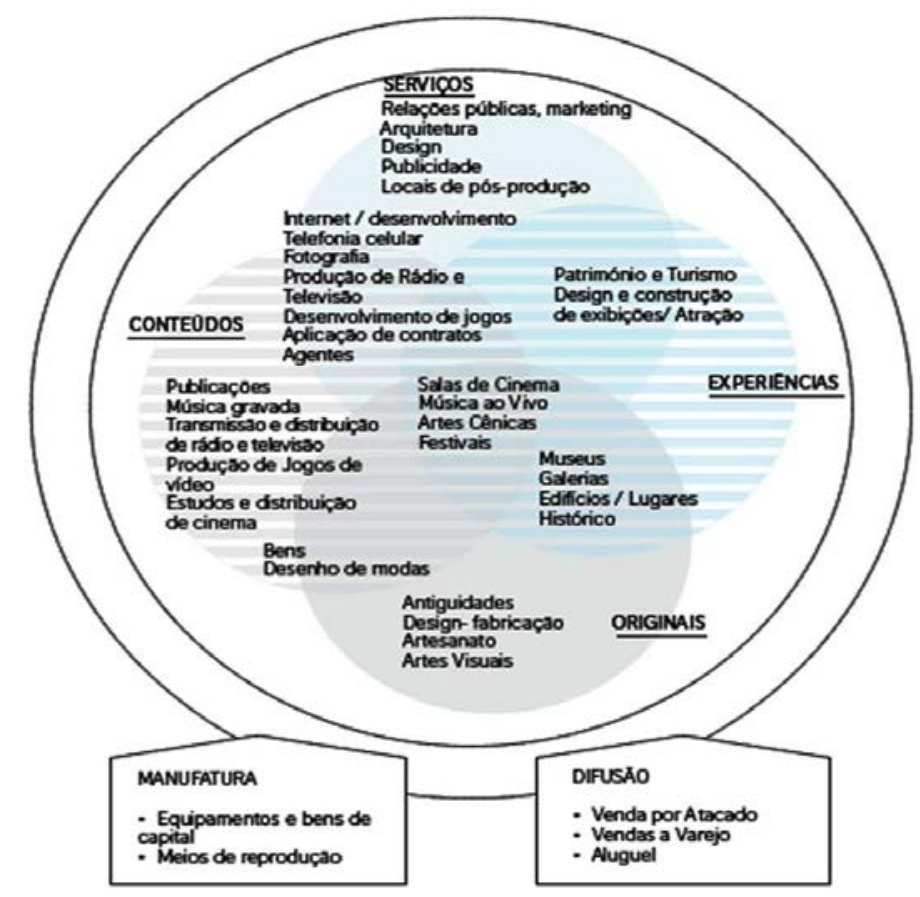

Imagem 5: Proposta de áreas para atividades criativas.

(Bop Consulting, 2010)

Neste contexto o objeto de estudos referenciado na antiga estação ferroviária de Cordeirópolis, estabelecida a relação com as áreas supramencionadas poderia abrigar - referencialmente após a recuperação parcial ou geral do conjunto - atividades como escritórios de arquitetura, design e publicidade (serviços criativos) em especial ligados ao ramo cerâmico, como a especificação e projeto de aplicação de materiais, design de pisos e revestimentos e mesmo na área de divulgação e marketing dos produtos, tanto através da implantação de escritórios e prestadores de serviços, quanto na instalação de cursos, formação de mão de obra e desenvolvimento de matéria prima e produtos.

Também poderiam estar ali instalados laboratórios profissionais e atividades educativas nas áreas de música, áudio e vídeo (conteúdos criativos) atrelados à produção e divulgação estabelecida no primeiro conceito dos serviços criativos. Cabe ressaltar que o município já conta com o "Projeto Guri" que em uma de suas vertentes já realiza cursos que ensinam a arte dos instrumentos musicais promovidos pela Secretaria Municipal da Cultura em parceria com os governos federal e estadual, que já tem capacidade para oferecer alunos e profissionais para as atividades propostas.

No ramo das experiências criativas o município poderia se apropriar de espaços para a instalação de um museu que abrigasse sua história e a da ferrovia, além de exposições referenciadas na história da ocupação regional esta representada pelos acervos das antigas fazendas de café como a Ibicaba e a Santa Gertrudes, ainda hoje preservadas, bem como de área para a realização de feiras e eventos que possam estabelecer um maior conhecimento acerca dos produtos, cultura e história locais e regionais.

Destaca-se ainda a oportunidade em se ampliar as atividades ligadas ao artesanato, as antiguidades e as artes visuais (originais criativos), abrindo espaços para a ampliação da capacidade de geração de emprego e renda local e, em especial, para a expansão da cultura criativa local.

Assim, ter-se-ia ainda os processos de interseção entre as áreas criativas, que promoveriam dinâmicas ao espaço da Antiga Estação, ampliando os usos daquele local e ainda de outros espaços existentes na cidade, como o Teatro, o antigo salão do "Cordeiro Clube" e sua sede esportiva, trazendo recursos para a efetivação da melhoria econômica e socioespacial de todo o município. 


\section{CONSIDERAÇÕES}

Sem perder de vista as atividades produtivas no município e, tendo como foco a Área da Estação propõe-se aplicar os conceitos de criatividade como instrumentos para explorar alguns dos recursos disponíveis no plano local como a mão de obra, o potencial dos setores cerâmico e logístico e a posição estratégica no plano regional, atrelados às questões histórica e cultural local.

Procurou-se desta maneira propostas pautadas em caracterizar e integrar fatores como a criatividade, a cultura e a produção - esta com foco na questão dos arranjos produtivos locais - de modo a propor atividades para a área da estação que possam contribuir com a construção de uma metodologia voltada ao reconhecimento, gestão e exploração dos recursos presentes no município.

Assim, as tratativas propostas para a área da antiga estação ferroviária de Cordeirópolis buscaram contemplar as condicionantes culturais e também as questões produtivas locais, no sentido de apresentar propostas para a evolução da economia criativa e também da justiça social, pautadas no planejamento urbano sustentável, inteligente e criativo.

Muitos dois as autores estudados abordam em seus estudos que no planejamento da cidade criativa faz-se essencial a valorização do espaço urbano pautada na ampliação da capacidade de espaços públicos e privados de promover a sociabilização da distribuição de oportunidades aos ocupantes da cidade, como materialidades capazes de dinamizar as relações socioespaciais de modo equilibrado, garantindo a mitigação da luta de classes pela apropriação dos resultados do capital.

Entende-se desta maneira que a melhoria nas condições de infraestrutura local na área da Estação pode acarretar aprimoramento na ocupação do solo da região central da cidade, pautada ainda na oferta de serviços públicos e privados, bem como na ampliação dos espaços de lazer, turismo, cultura e educação, atraindo assim para a área em questão, demanda impulsionada pelo atendimento de suas necessidades e portanto disposta à obtenção de atendimento, o que poderá gerar emprego e renda.

Com o acesso ao emprego e a renda, a população residente na área da Estação teria a oportunidade de ocupar imóveis com financiamento acessível e promovido pelo poder público em outras porções urbanas e as antigas casas da ferrovia localizadas junto à gare, bem como as sub-habitações existentes entre as mesmas - estas removidas - poderiam dar lugar aos serviços públicos municipais ora ocupantes de imóveis locados pela Prefeitura na cidade.

Também é notável no mundo globalizado, em especial nas culturas tradicionais, o interesse em resgatar ícones da cultura popular, sem perder de vistas as características primitivas destes símbolos, em especial no que tange o contexto da inovação.

Projetos de arquitetura ao redor do mundo resgatam a cultura local interpretando suas características em obras inovadoras sob o aspecto tecnológico, mas de soluções simples atreladas aos aspectos climáticos e representativos atrelados ao costume e a aplicação de materiais de construção.

A questão da requalificação sob o ponto de vista cultural deve passar então pela promoção de espaços onde as atividades culturais possam tomar corpo e se desenvolver, tanto abertos, com funções de praça e área de convívio, quanto fechados como salas de espetáculos e exposições.

Desta maneira entende-se que Cordeirópolis tem potencialidade relacionada à cultura local, com produção de eventos e atividades na área, mas faz-se necessário pensar em políticas de gestão públicas, estas com capacidade para atrais também a iniciativa privada, com foco no desenvolvimento da economia criativa.

Para que esta evolução não seja relegada a um plano inferior é possível aproveitar-se a oportunidade para a requalificação da área da antiga Estação, sob o foco criativo, demonstrando habilidades para auferir a riqueza cultural e criativa disponível no plano local, e buscar efetivar o talento criativo.

Neste cenário local, cabe ainda apontar a questão da requalificação urbana, processo projetual e de planejamento que venha a propiciar um sentido de qualidade a um determinado local onde esta se encontra ausente ou deficitária, fazendo com este adquira uma dinâmica diferenciada em relação ao uso presente e volte a exercer sua função socioespacial inclusive em relação ao seu entorno urbano. 
Deste modo, ainda que não exerça mais sua função original, o espaço e seu entorno local e até mesmo regional, poderão oferecer um escopo de atividades que tragam de volta a dinâmica ao socioespaço como um todo.

Como instrumento de intervenção, a economia criativa teria então, atrelada ao planejamento urbano, o papel de impulsionar o sentimento de identidade que o socioespaço representa para a comunidade.

Esta identificação, no caso da antiga Estação Ferroviária em Cordeirópolis teria, por exemplo, tal representatividade pautada em se constituir a área como um ponto de encontro e convívio das pessoas, neste período não como o local de chegadas e partidas, mas de encontro e conjunção de ideias.

\section{BIBLIOGRAFIA}

CRIONI, A. G. O (2012). Patrimônio cultural e identidade territorial: estudo do bairro de Cascalho Cordeirópolis - SP. (138f) Dissertação (Mestrado em Geografia) Instituto de Geociências e Ciências Exatas. Rio Claro: Universidade Estadual paulista Julio de Mesquita Filho.

HOWKINS, J. (2011). Ecologias criativas. In.: REIS, Ana Carla Fonseca; KAGEYAMA, Peter, (Orgs.). Cidades criativas: perspectivas (124-129). São Paulo: Garimpo de Soluções.

LACERDA, D. (2015a) Ainda sem tratamento, esgoto de Cordeirópolis tem 500 kg de lixo. In: Gazeta de Limeira, Limeira, p. 10, 26. Jul. 30. Jul.

(2015b). Conta de água fica 25,62\% mais cara em Cordeirópolis. In: Gazeta de Limeira, Limeira, p. 5,

LANDRY, C. (2013). Origens e futuro da cidade criativa. São Paulo: SESI.

LEVIGHIN, S.C. (2005). Problemas e impactos provocados pela atividade ceramista nos municípios de Santa Gertrudes e Cordeirópolis. (210 f). Tese (Doutorado em Geografia). Instituto de Geociências e Ciências Exatas. Rio Claro: Universidade Estadual paulista Julio de Mesquita Filho.

SOUZA, M. L. (2003). Mudar a cidade: uma introdução crítica ao planejamento e à gestão urbanos. 2. Ed. Rio de Janeiro: Bertrand Brasil.

UNIVERSIDADE FEDERAL DE SÃO CARLOS (UFSCAR) (2007). Leitura técnica da realidade municipal: Cordeirópolis/SP. (150f). São Carlos: UFSCar.

\section{Fontes eletrônicas}

BOP CONSULTING (2010). Guia Prático para o mapeamento das indústrias criativas. Trad. Diana Marcela Rey e João Loureiro. Londres: British Council.

http://creativeconomy.britishcouncil.org/media/uploads/files/Mapping_guide_-_Portuguese.pdf (Consulta: 07/01/2016)

CETESB, Companhia Ambiental do Estado de São Paulo (2015). Qualidade do ar no estado de São Paulo 2014. São Paulo: CETESB. http://ar.cetesb.sp.gov.br/wp-content/uploads/sites/37/2013/12/rqar_2014.pdf (Consulta:29/05/2015).

IVERSEN, Lisbeth (2011). Desenvolvimento urbano, clima e meio ambiente como vantagens competitivas. In: REIS, Ana Carla Fonseca; KAGEYAMA, Peter (Orgs.).Cidades criativas: perspectivas. São Paulo: Garimpo de Soluções. http://garimpodesolucoes.com.br/wp-content/uploads/2012/10/CCP-PT-final.pdf (Consulta: 05/03/ 2014).

NEWBIGIN, John (2010). A economia criativa: um guia introdutório. Série Economia Criativa e Cultural / 1. Trad. Diana Marcela Rey e João Loureiro. Londres: British Concil.

http://creativeconomy.britishcouncil.org/media/uploads/files/Intro_guide_-_Portuguese.pdf (Consulta: 13/10/.2015). 
Pascon, José Roberto (2013). Estações ferroviárias: Cordeirópolis.

http://www.estacoesferroviarias.com.br/c/cordeiropolis.htm (Consulta: 25/01/2013).

SANCHES, Renan (2014). Parcelamentos e ocupações irregulares. 148f. Monografia (Graduação em Engenharia Civil) - Faculdade de Engenharia Civil, Faculdades Integradas Einstein, Limeira.

http://www.einsteinlimeira.com.br/p/comissoes/162 (Consulta: 29/03/.2015).

TREVISAN, Cláudia (2014). A destruição do sonho americano de Detroit. In: Jornal "O Estado de S.

Paulo", São Paulo, 5.jan.2014. Economia, B6 e B7. http://economia.estadao.com.br/noticias/geral,adestruicao-do-sonho-americano-de-detroit,174417e (Consulta: 05/05/2015).

VASQUES, Amanda Ramalho (2005). Refuncionalização de Brownfields: estudo de caso na zona leste de São Paulo-SP. 160 f. Dissertação (mestrado) - Universidade Estadual Paulista, Instituto de Geociências e Ciências Exatas. http://hdl.handle.net/11449/95620 (Consulta: 26/11/2015). 